\title{
Farelo de tungue in natura ou detoxificado na alimentação de carpa húngara (Cyprinus carpio)
}

[In natura or detoxified tung meal in feeding Hungarian carp (Cyprinus carpio)]

\author{
A. Pretto ${ }^{1}$, L.P. Silva ${ }^{2}$, F.R. Goulart ${ }^{3}$, E.K. Battisti ${ }^{3}$, B.B. Loureiro ${ }^{3}$, \\ D.P. Eggers ${ }^{3}$, D. Pianesso ${ }^{3}$ \\ ${ }^{1}$ Unipampa - Dom Pedrito, RS \\ ${ }^{2}$ Universidade Federal de Santa Maria - Santa Maria, RS \\ ${ }^{3}$ Aluno de pós-graduação - Universidade Federal de Santa Maria - Santa Maria, RS
}

\begin{abstract}
RESUMO
Este estudo avaliou a substituição parcial de farinhas de origem animal pelo farelo de tungue como fonte proteica no arraçoamento de carpa húngara. Os tratamentos compreenderam a inclusão de farelo de tungue in natura ou detoxificado (obtido após aplicação de tratamento químico ao farelo), e o tratamento referência consistiu de base proteica composta por farinha de carne e ossos suína e farinha de peixe. O período de alimentação foi de 63 dias. No decorrer de 30 dias experimentais não foi observada diferença em indicadores de crescimento entre os animais que consumiram as rações controle e com farelo de tungue tratado quimicamente, porém o consumo da ração com farelo de tungue in natura provocou redução no desempenho até o final do período experimental. Após 63 dias de arraçoamento, alguns indicadores de crescimento mostraram-se inferiores também para o tratamento que continha farelo de tungue tratado em relação ao controle. A análise bioquímica no plasma e no fígado revelou aumento de triglicerídeos, glicogênio, glicose e a utilização de outras fontes, possivelmente aminoácidos, como precursores energéticos na produção de energia quando os animais consumiram a dieta com farelo de tungue in natura em relação às demais, o que refletiu na menor concentração de proteína e na maior deposição de gordura na carcaça. Em relação à atividade de enzimas digestivas, tripsina apresentou atividade aumentada no tratamento com farelo de tungue in natura e protease ácida, quimotripsina, amilase e lipase não foram alteradas em nenhum dos tratamentos avaliados.
\end{abstract}

Palavras-chave: peixes, proteína vegetal, antinutrientes, crescimento, metabolismo

\begin{abstract}
This study evaluated the partial replacement of animal meal by tung meal as protein source in feeding Hungarian carp. The treatments consisted of the inclusion of in natura or detoxified tung meal (obtained after chemical treatment applied to tung meal) as well as the reference treatment in which the protein basis was composed of meat and bone pork meal and fish meal. The feeding period was 63 days. During 30 experimental days no difference was observed in growth indicators among animals fed the control diet or with chemically treated tung meal, however, the consumption of diets with in natura tung meal caused reduced performance until the end of the experimental period. After 63 days of feeding, some growth indicators were also are lower for the treatment containing treated tung meal compared to control. Biochemical analysis in plasma and liver revealed increased triglycerides, glycogen, glucose and use of other sources, possibly amino acids, as precursors in the production of energy when animals consumed the diet with in nature tung meal in relation to others, which reflected in lower levels of protein and higher fat deposition in the carcass. Regarding the activity of digestive enzymes, trypsin showed increased activity in the treatment with in natura tung meal and acid protease, chymotrypsin, amylase and lipase were not changed in any of the treatments.
\end{abstract}

Keywords: fish, vegetable protein, antinutrients, growth, metabolism

Recebido em 25 de outubro de 2012

Aceito em 25 de junho de 2014

E-mail: ale.pretto@yahoo.com.br 


\section{INTRODUÇÃO}

Dados do Ministério da Pesca e Aquicultura (2012) revelam que a criação de carpas ocupa o segundo lugar na produção brasileira de peixes, correspondendo a $24 \%$ do total, o que assume especial importância em estados como o Rio Grande do Sul, onde as carpas respondem por $90 \%$ da produção de pescado. O cultivo de uma das principais espécies, a carpa húngara, baseia-se na criação semi-intensiva, por meio da utilização de coprodutos agroindustriais ou consórcio com atividades agropecuárias (Tamassia et al., 2004). Entre as formas de otimizar o ciclo de produção da espécie, destaca-se o fornecimento de dietas balanceadas, que suprem adequadamente as exigências nutricionais, sobretudo em etapas iniciais de desenvolvimento como a alevinagem (Kaushik, 1995; Bergamin et al., 2011).

Na elaboração de dietas para piscicultura, vários estudos têm apontado para a redução na inclusão de ingredientes proteicos de origem animal, seja pelo custo elevado ou pela variável composição nutricional dessas fontes (Bureau et al., 2000; Hardy, 2010). Nesse cenário, ingredientes vegetais, como farelo de soja, de girassol, de canola, têm sido incorporados de forma isolada ou em combinação, a fim de substituir fontes de origem animal na nutrição de peixes (El-Saidy e Gaber, 2003; Kaushik et al., 2004). Da mesma maneira, outros coprodutos agroindustriais começam a surgir no mercado, principalmente oriundos da cadeia de biocombustíveis, os quais exigem estudos para atestar seu potencial nutricional e os níveis de inclusão alimentar.

O tungue (Aleurites fordii) é apontado como cultura com grande potencial para diversificar a matriz produtiva do biodiesel, devido ao rendimento e à qualidade do óleo extraído (Kautz et al., 2008). Pela dependência de clima temperado, o seu cultivo está sendo fortemente fomentado nos estados do Sul do país. O farelo resultante da extração do óleo presente no fruto apresenta teor elevado de proteína. No entanto, não há relatos da utilização desse ingrediente na nutrição animal, possivelmente devido à falta de informações sobre sua composição química detalhada. Por isso, o objetivo deste estudo foi verificar características bromatológicas do farelo de tungue e avaliar sua inclusão (forma in natura ou tratado quimicamente) sobre desempenho produtivo, parâmetros digestivos, metabólicos e composição corporal de carpa húngara.

\section{MATERIAL E MÉTODOS}

Amostras de farelo de tungue obtidas após a extração do óleo foram avaliadas para matéria seca $\left(105^{\circ} \mathrm{C}\right.$ em estufa por 24 horas), cinzas $\left(550^{\circ} \mathrm{C}\right.$ por seis horas), proteína bruta (nitrogênio total x 6,25) (Official..., 1995), gordura (Bligh e Dyer, 1959) e fibra em detergente neutro (FDN) (Van Soest et al., 1991). Entre os antinutrientes, foram analisados compostos fenólicos totais, taninos totais e condensados (Makkar, 2000). Compostos fenólicos foram extraídos com solução de acetona em banho de ultrassom e taninos totais extraídos com PVPP (polivinilpolipirrolidona), e suas respectivas concentrações determinadas por reação colorimétrica com o reagente Folin-Ciocalteau e solução aquosa de carbonato de sódio, utilizando-se ácido tânico como padrão. Taninos condensados foram quantificados utilizando-se butanol-ácido clorídrico e solução de sulfato de ferro e amônio em ácido clorídrico, ao extrato previamente obtido. A concentração de taninos hidrolisáveis foi obtida pela diferença entre o conteúdo de taninos totais menos os taninos condensados. O teor de ácido fítico (Latta e Eskin, 1980) foi quantificado utilizando-se resina de troca aniônica (Bio-RAd AG1-X4), após extração do antinutriente em solução de ácido clorídrico. O padrão empregado foi sal de ácido fítico (SIGMA, pureza de 90\%). Os demais ingredientes utilizados nas formulações foram previamente analisados em relação à composição nutricional, ao cálcio e ao fósforo (Pretto, 2013).

Para reduzir a concentração de antinutrientes do farelo de tungue, este foi pré-tratado sequencialmente com soluções ácida (adição de ácido sulfúrico em água até pH 1,0) e álcool comercial $92^{\circ}$ durante uma hora, com agitação constante. A solução resultante foi filtrada em peneiras de 100 e $25 \mu \mathrm{m}$, para separar a parte líquida da sólida. Antes da segunda filtragem, o $\mathrm{pH}$ da mistura foi elevado a 7,0. A recuperação das frações proteicas dissolvidas no meio líquido foi realizada por ponto isoelétrico (elevação do pH a 9,0 e redução a 4,5). A fração sólida do farelo e a fração proteica concentrada foram secas em estufa a $60^{\circ} \mathrm{C}$ durante 24 horas, constituindo o farelo detoxificado/tratado. 
O ensaio biológico foi conduzido no Laboratório de Piscicultura, Universidade Federal de Santa

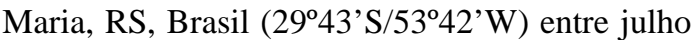
e setembro de 2011. Foram utilizados 15 juvenis de carpa comum, var. húngara, (médias de 41g e $13 \mathrm{~cm}$ ) por unidade experimental (tanques de 125L de volume útil de água), obedecendo à densidade de estocagem inicial de $\pm 5 \mathrm{~g} / \mathrm{L}$. O delineamento adotado foi o completamente ao acaso, com três tratamentos e três repetições: TgIN - farelo de tungue in natura; TgT - farelo de tungue tratado quimicamente e CON (controle), com a base proteica composta por farinha de carne e ossos suína e farinha de peixe (Tab. 1). O farelo de tungue foi incluído para substituir $20 \%$ da proteína de origem animal nas dietas formuladas para conter aproximadamente $34 \%$ de proteína bruta e 3100kcal/kg de energia digestível. As exigências de lisina e metionina foram baseadas no estudo de Montes-Girao e Fracalossi (2006), e, quando necessário, esses aminoácidos foram suplementados.

Tabela 1. Formulação e composição centesimal das dietas experimentais

\begin{tabular}{|c|c|c|c|}
\hline \multirow{2}{*}{ Ingredientes (\%) } & \multicolumn{3}{|c|}{ Tratamentos $^{1}$} \\
\hline & $\mathrm{CON}$ & TgIN & TgT \\
\hline Farinha de peixe & 12,50 & 9,84 & 9,73 \\
\hline Farinha de carne suína & 43,50 & 35,00 & 34,80 \\
\hline Farelo tungue in natura & - & 32,45 & - \\
\hline Farelo de tungue tratado & - & - & 32,45 \\
\hline Farelo de trigo & 12,95 & 3,80 & 3,20 \\
\hline Milho & 16,24 & 5,90 & 2,95 \\
\hline Amido de milho & 2,04 & 3,80 & 7,21 \\
\hline Óleo de soja & 4,00 & 6,18 & 6,62 \\
\hline Sal & 0,50 & 0,50 & 0,50 \\
\hline Fosfato bicálcico & - & - & - \\
\hline Mistura vitaminas/minerais ${ }^{2}$ & 2,00 & 2,00 & 2,00 \\
\hline Metionina & 0,54 & 0,50 & 0,53 \\
\hline Carbonato de cálcio & - & 0,03 & 0,01 \\
\hline Inerte & 5,73 & - & - \\
\hline Proteína bruta ${ }^{3}(\%)$ & 33,91 & 33,84 & 33,97 \\
\hline Gordura $^{3}(\%)$ & 12,45 & 13,38 & 13,00 \\
\hline $\operatorname{Cinzas}^{3}(\%)$ & 15,14 & 13,79 & 13,82 \\
\hline Fibra em detergente neutro ${ }^{3}(\%)$ & 6,62 & 17,28 & 19,94 \\
\hline Carboidratos $^{4}(\%)$ & 14,16 & 8,26 & 5,39 \\
\hline Energia digestível $^{5}$ (kcal/kg) & 3070 & 3048 & 3063 \\
\hline Cálcio $^{3}(\%)$ & 2,26 & 3,07 & 2,30 \\
\hline Fósforo total ${ }^{3}(\%)$ & 1,37 & 1,87 & 1,40 \\
\hline Relação Ca:P & 1,66 & 1,64 & 1,64 \\
\hline $\operatorname{Lisina}^{3}(\%)$ & 1,78 & 1,69 & 1,70 \\
\hline Metionina $^{3}(\%)$ & 1,25 & 1,25 & 1,26 \\
\hline
\end{tabular}

${ }^{\mathrm{T}} \mathrm{CON}=$ ração controle, com a base proteica constituída por farinhas de origem animal; TgIN=inclusão de farelo de tungue in natura; TgT=inclusão de farelo de tungue tratado quimicamente. ${ }^{2}$ Composição da mistura vitamínica por kg de produto. Ác. fólico: 1200mg; ác. nicotínico: 24000mg; ác. pantotênico: 12000mg; biotina: 48mg; vit.A: 1200000UI; vit. B1: 4800mg; vit. B2: 4800mg; vit. B6: 4800mg; vit. B12: 4800mcg; vit. C: 48g; vit. D3: 200000UI; vit. E: 12000mg; vit. K3: 2400mg; cobalto: 10mg; cobre: 3000mg; ferro: 50000mg; iodo: 100mg; manganês: 20000mg; selênio: 100mg; zinco: 3000mg.

${ }^{3}$ Calculado com base na análise dos ingredientes. ${ }^{4}$ Carboidratos solúveis em detergente neutro calculado: 100(proteína bruta+matéria mineral+lipídeos+fibra em detergente neutro+umidade).

${ }^{5}$ Calculada com a fórmula: (proteína*5,64*0,83)+(lipídeo*9,44*0,88)+(carboidrato*4,11*0,65))*10 (Meyer et al., 2004).

O sistema de criação usado foi de recirculação de água, com dois filtros biológicos contendo pedra britada e duas resistências elétricas (1000W) para manutenção da temperatura. Os peixes foram aclimatados às condições experimentais durante uma semana e posteriormente alimentados 
durante 63 dias. A dieta, fornecida em torno de $3,5 \%$ da biomassa de cada tanque, foi fracionada em três refeições diárias (nove, 13 e 17 horas). As unidades experimentais foram limpas diariamente, por meio de sifonagens (oito horas e 15h30). Foram retiradas fezes e sobras de ração e renovou-se cerca de $10 \%$ da água do tanque em cada procedimento de limpeza.

Para o controle da qualidade da água, realizou-se a aferição diária da temperatura (manhã $21,42 \pm 0,88^{\circ} \mathrm{C}$ e tarde $22,09 \pm 0,82^{\circ} \mathrm{C}$ ) e semanalmente o oxigênio dissolvido $(4,75 \pm 0,55 \mathrm{mg} / \mathrm{L}) \quad$ (oxímetro digital modelo 550A, YSI, Yellowsprings, USA); $\mathrm{pH}$ $(6,82 \pm 0,14)$ (pHmetro modelo MPA 210-P, Servilab, Brasil); amônia não ionizada $(0,11 \pm 0,09 \mathrm{mg} / \mathrm{L})$ (Verdouw et al., 1978); nitrito $(0,05 \pm 0,01 \mathrm{mg} / \mathrm{L})$, alcalinidade $(20,78 \pm 5,32 \mathrm{mg} / \mathrm{L}$ $\left.\mathrm{CaCO}_{3}\right)$ e dureza $\left(43,56 \pm 10,28 \mathrm{mg} / \mathrm{L} \quad \mathrm{CaCO}_{3}\right)$, determinados de acordo com Boyd e Tucker (1992).

As biometrias foram realizadas aos 30 e 63 dias experimentais. Para tanto, os peixes foram mantidos em jejum durante $18 \mathrm{~h}$ e anestesiados com eugenol (20-30 $\mu \mathrm{L}$ de extrato puro/L água) (Neu et al., 2009). Assim, foram obtidos dados de peso médio (PM), comprimento total (CT), fator de condição (FC), ganho médio diário (GMD), taxa de crescimento específico (TCE), biomassa (BM), sobrevivência (S) e conversão alimentar (CA). Ao final do período experimental, após permanecerem em jejum, dois peixes de cada caixa (seis por tratamento) foram capturados para coleta de sangue (na veia caudal, com seringas heparinizadas) e, logo após, eutanasiados (punção na medula espinhal), eviscerados para remover o trato digestivo e o fígado, e os tecidos congelados $\left(-18^{\circ} \mathrm{C}\right)$ para análise de enzimas digestivas e parâmetros bioquímicos no fígado. Alíquotas de plasma foram separadas após centrifugação do sangue (10min a 1200g), para determinação de metabólitos.

As secções do trato digestivo (estômago e intestino total) foram homogeneizadas (proporção tecido:tampão homogeneização 1:20) em homogeneizador de tecidos tipo Turrax (modelo MA 102, Marconi, Brasil). A solução de homogeneização continha Tris amino metano 0,02M e fosfato de potássio 0,01M, a pH 7,5 em $50 \%$ de glicerol (v/v). Os homogeneizados foram centrifugados (10min a $1200 \mathrm{~g})$, e o sobrenadante utilizado como fonte enzimática. No estômago, foi avaliada a atividade de protease ácida, e, no intestino, tripsina, quimotripsina e $\alpha$-amilase, conforme as metodologias descritas em Lazzari et al. (2010). Para avaliar a atividade de lipase intestinal (Gawlicka et al., 2000), utilizou-se o substrato $p$-nitrophenyl meristato. O conteúdo de proteína para expressar a atividade enzimática das amostras foi determinado pelo método de Bradford (1976), e foi usada albumina bovina com padrão.

No fígado, foram determinados glicogênio, açúcares redutores e aminoácidos, conforme metodologias descritas em Pretto (2013), proteína total (Bradford, 1976) e amônia (Verdouw et al., 1978). Alanina aminotransferase (ALT) e aspartato aminotransferase (AST) foram avaliadas seguindo-se os protocolos descritos em kits colorimétricos (Doles Reagentes e Equipamentos Laboratoriais Ltda., Goiânia, Goiás, Brasil) após diluição do extrato bruto em tampão (solução de fosfato de potássio 20mM, pH 7,5), respectivamente, duas e 10 vezes. Todos os extratos hepáticos foram preparados na proporção 1:20 de tecido:solução de homogeneização. Glicose, proteínas totais, albumina, triglicerídeos e colesterol plasmáticos foram analisados utilizando-se kits colorimétricos (Doles), e os procedimentos seguiram o protocolo específico para cada parâmetro. A concentração de aminoácidos no plasma foi quantificada segundo metodologia descrita em Pretto (2013).

No início e no final do experimento, dois peixes de cada unidade experimental foram anestesiados, conforme descrição anterior, e abatidos em água e gelo (proporção 1:1) para análise da composição centesimal no peixe inteiro. As amostras foram trituradas em multiprocessador de alimentos e mantidas a $18^{\circ} \mathrm{C}$ até a análise de matéria seca, cinzas, proteína bruta e gordura, conforme metodologias previamente descritas.

Na análise estatística, os dados foram submetidos à ANOVA de uma via, em seguida pelo teste $\mathrm{F}$ para comparar as médias entre os tratamentos contendo a forma in natura em relação à forma tratada do farelo de tungue. A comparação de todos os tratamentos com o controle foi realizada 
por meio do teste de Dunnett. Os dados estão expressos como média \pm erro-padrão da média, e as diferenças consideradas significantes com $\mathrm{P}<0,05$. O programa estatístico SPSS, versão 8.0 foi utilizado para realização das análises estatísticas.

Todos os procedimentos envolvendo animais foram conduzidos segundo a aprovação do Comitê de Ética e Bem-Estar Animal da Universidade Federal de Santa Maria (protocolo número 026/2011-2).

\section{RESULTADOS E DISCUSSÃO}

A composição bromatológica do farelo de tungue in natura revelou concentração de cinzas, proteína, gordura e FDN, respectivamente, de 7,02; 27,96; 3,34 e 52,25\%. Em relação a fenóis totais, taninos totais, taninos condensados, taninos hidrolisáveis e ácido fítico, os resultados foram, respectivamente, 1,23; 1,09; 0,025; 1,07 e $1,63 \%$. Após o tratamento químico, o farelo apresentou resultados muito semelhantes em relação a cinzas e proteína, mas ocorreu aumento na concentração de FDN (11\%), fenóis totais $(12 \%)$, taninos totais $(9,75 \%)$ e taninos hidrolisáveis (10,5\%). A elevação no teor desses antinutrientes possivelmente está relacionada ao aumento de fibra do farelo, fração à qual essas moléculas estão associadas. No entanto, foi reduzido o teor de gordura (-66\%), taninos condensados (-28\%) e ácido fítico (-62\%).

Essas alterações em nutrientes e antinutrientes tiveram reflexos sobre respostas zootécnicas e metabólicas quando as distintas formas do farelo de tungue (in natura ou tratado quimicamente) foram usadas em substituição parcial às fontes proteicas de origem animal nas rações para carpa húngara. Após 30 dias de alimentação, os animais que receberam a ração com farelo de tungue tratado (TgT) apresentaram desempenho superior àqueles alimentados com ração contendo farelo de tungue in natura (TgIN) quanto ao PM, CT, GMD e TCE, não diferindo do controle (CON). A CAA foi superior para os animais do tratamento TgIN, mas o fator de condição não diferiu entre os tratamentos avaliados (Tab. 2).

Tabela 2. Desempenho de juvenis de carpa húngara alimentados com dieta à base de proteína de origem animal (controle) ou contendo farelo de tungue in natura ou tratado quimicamente

\begin{tabular}{|c|c|c|c|}
\hline \multirow{2}{*}{ Variáveis $^{1}$} & \multicolumn{3}{|c|}{ Tratamentos } \\
\hline & $\mathrm{CON}$ & TgIN & TgT \\
\hline \multicolumn{4}{|c|}{30 dias } \\
\hline$P(g)$ & $69,28 \pm 9,13$ & $60,06 \pm 8,22^{a}$ & $67,08 \pm 9,67 *$ \\
\hline CT (cm) & $15,21 \pm 0,71$ & $14,73 \pm 0,65^{\mathrm{a}}$ & $15,01 \pm 0,62 *$ \\
\hline GMD (g/dia) & $0,91 \pm 0,02$ & $0,57 \pm 0,04^{\mathrm{a}}$ & $0,86 \pm 0,04^{*}$ \\
\hline TCE (\%/dia) & $1,68 \pm 0,02$ & $1,12 \pm 0,07^{\mathrm{a}}$ & $1,62 \pm 0,06 *$ \\
\hline FC & $1,97 \pm 0,02$ & $1,88 \pm 0,02$ & $1,98 \pm 0,04$ \\
\hline CAA & $2,23 \pm 0,10$ & $3,45 \pm 0,17^{\mathrm{a}}$ & $2,67 \pm 0,26$ \\
\hline SOB (\%) & 66,67 & 91,11 & 82,22 \\
\hline $\mathrm{BM}(\mathrm{g})$ & $692,17 \pm 35,24$ & $820,06 \pm 8,39^{a}$ & $849,27 \pm 14,74^{a}$ \\
\hline \multicolumn{4}{|c|}{63 dias } \\
\hline $\mathrm{P}(\mathrm{g})$ & $107,22 \pm 2,11$ & $77,17 \pm 3,94^{\mathrm{a}}$ & $93,00 \pm 1,92^{* a}$ \\
\hline CT (cm) & $17,42 \pm 0,12$ & $15,94 \pm 0,18^{\mathrm{a}}$ & $16,51 \pm 0,09 *^{\mathrm{a}}$ \\
\hline GMD (g/dia) & $1,15 \pm 0,05$ & $0,52 \pm 0,08^{\mathrm{a}}$ & $0,79 \pm 0,03^{* a}$ \\
\hline TCE (\%/dia) & $1,32 \pm 0,04$ & $0,75 \pm 0,09^{\mathrm{a}}$ & $0,99 \pm 0,03^{* a}$ \\
\hline $\mathrm{FC}$ & $2,03 \pm 0,01$ & $1,90 \pm 0,03^{\mathrm{a}}$ & $2,06 \pm 0,01 *$ \\
\hline CAA & $2,24 \pm 0,06$ & $4,30 \pm 0,24^{\mathrm{a}}$ & $3,05 \pm 0,11^{* a}$ \\
\hline SOB (\%) & 66,67 & 91,11 & 82,22 \\
\hline $\mathrm{BM}(\mathrm{g})$ & $857,48 \pm 63,33$ & $897,93 \pm 23,63$ & $990,96 \pm 18,05 *$ \\
\hline
\end{tabular}

${ }^{1} \mathrm{P}=$ peso; CT=comprimento total; GMD=ganho médio diário; TCE=taxa de crescimento específico; FC=fator de condição; CAA=conversão alimentar aparente; SOB=sobrevivência acumulada; BM=biomassa. Valores expressos como média \pm erro-padrão da média $(\mathrm{n}=3)$. *Indica diferença significativa da forma tratada quimicamente para a forma in natura do farelo pelo teste $\mathrm{F}(\mathrm{P}<0,05)$. Letra indica diferença significativa em relação ao tratamento controle pelo teste de Dunnett $(\mathrm{P}<0,05)$. 
Ao final do período experimental, o tratamento TgT continuou proporcionando desempenho superior aos animais para todos os parâmetros em relação ao tratamento TgIN, mas, com exceção do FC e BM, os demais parâmetros foram inferiores ao controle (Tab. 2). O desempenho produtivo em estudos com substituição de proteína de origem animal por fontes vegetais mostra-se variável de acordo com a espécie, o ingrediente e o nível de inclusão. Por exemplo, juvenis de carpa húngara apresentaram menor crescimento quando a proteína da farinha de carne e ossos suína foi substituída parcialmente (50\%) pelos farelos de soja, canola ou linhaça (Bergamin et al., 2011). Essa resposta também foi demonstrada por alevinos dessa espécie após a substituição total da farinha de peixe por farelo de soja ou girassol (Khan et al., 2003). A pior resposta no desempenho produtivo pode estar relacionada aos antinutrientes presentes, à menor digestibilidade e disponibilidade de nutrientes oriundos da digestão dessas fontes, especialmente aminoácidos, além da reduzida palatabilidade dos ingredientes proteicos vegetais quando comparados àqueles de origem animal (Hansen et al., 2007).

Neste estudo, após 63 dias de alimentação, os animais que receberam a ração controle apresentaram desempenho superior, porém a aplicação do tratamento químico ao farelo de tungue proporcionou melhor resposta de crescimento em relação àqueles arraçoados com a forma in natura do farelo. Possivelmente, a redução de antinutrientes como ácido fítico e taninos condensados contribuiu para esse fato. Além disso, acredita-se que o tratamento aplicado tenha reduzido a concentração de ésteres de forbol, que são substâncias tóxicas presentes em exemplares da família Euphorbiaceae, à qual pertence o tungue, contribuindo para melhoria no valor nutricional e na palatabilidade do farelo. Similarmente, foi observado que a detoxificação mais efetiva do farelo de pinhão manso (Jatropha curcas), a fim de retirar ésteres de forbol, e posteriormente a substituição parcial (50\%) da farinha de peixe por esse farelo na dieta de alevinos de carpa comum acarretaram crescimento similar à dieta controle (Kumar et al., 2011).

Alterações no perfil ou na concentração de enzimas digestivas podem ocorrer devido à fonte alimentar ou à quantidade de nutrientes na dieta, o que influencia decisivamente a digestão e a absorção dos alimentos (Lin e Luo, 2011). Dessa forma, a resposta no crescimento animal pode ser suportada por parâmetros relacionados à digestão e ao metabolismo de proteínas e carboidratos. Neste estudo, não foram observadas diferenças em relação às enzimas digestivas entre os peixes alimentados com as rações contendo farelo de tungue nas diferentes formas, mas observou-se aumento na atividade de tripsina nos peixes que receberam o tratamento TgIN comparado ao CON (Tab. 3).

Este dado é contrário à maioria dos resultados experimentais com peixes, em que se observa redução na atividade de proteases, lipases e amilases após a inclusão de ingredientes de origem vegetal na dieta, decorrente da ação de fatores antinutricionais (Lazzari et al., 2010; Lin e Luo, 2011). No entanto, este resultado pode representar um mecanismo compensatório dos animais para tolerar a menor digestibilidade e o valor nutricional do farelo in natura, especialmente em relação à proteína.

A bioquímica plasmática também revelou maiores concentrações de proteína, aminoácidos e triglicerídeos nos animais que receberam o tratamento TgIN em relação ao controle (Tab. 3). Entre os peixes alimentados com as rações contendo farelo de tungue, observou-se menor nível de glicose e maior concentração de triglicerídeos no tratamento TgIN em comparação ao TgT, enquanto os níveis de albumina e colesterol não foram alterados pelos distintos tratamentos. Considerando os parâmetros analisados no fígado, a reserva de glicogênio foi superior nas carpas alimentadas com o tratamento TgIN comparado ao CON. Em relação à dieta TgT, foi observado maior teor de glicogênio, glicose e AST (Tab. 3). Os animais que consumiram a ração TgT apresentaram menor concentração de AST em relação aos arraçoados com o tratamento controle. Os teores de proteína, aminoácidos, amônia e ALT não foram alterados. Os resultados observados no tratamento TgIN demonstram uma situação de reserva energética no fígado, possivelmente relacionada aos elevados teores de proteína e aminoácidos no plasma, que podem servir como precursores para produção de energia na rota gliconeogênica. Neste tratamento, foi verificado o menor crescimento das carpas, fato que está 
ligado à presença dos antinutrientes na fonte, que reduzem a eficiência no aproveitamento do alimento e contribuem com o desbalanço dos nutrientes absorvidos, principalmente os aminoácidos, que, em vez de constituírem proteína muscular, são desaminados e convertidos em energia. Resultados similares foram observados após a incorporação de proteína vegetal na dieta de salmão (Salmo salar)
(Pratoomyot et al., 2010). O aumento na atividade da AST também é indicativo do direcionamento de aminoácidos para síntese de precursores energéticos. Por outro lado, a menor concentração de AST no tratamento TgT pode indicar uma situação contrária em relação ao uso de proteína como fonte de energia, e sim a utilização de glicogênio e fontes lipídicas para este fim.

Tabela 3. Parâmetros digestivos, bioquímica plasmática e hepática em juvenis de carpa húngara alimentados durante 63 dias com dieta à base de proteína de origem animal (controle) ou contendo farelo de tungue in natura ou tratado quimicamente

\begin{tabular}{cccc}
\hline & \multicolumn{3}{c}{ Tratamentos } \\
\cline { 2 - 4 } Variáveis $^{1}$ & CON & TgIN & TgT \\
\cline { 2 - 4 } & \multicolumn{2}{c}{ Enzimas digestivas } & $2,66 \pm 0,27$ \\
Amilase & $2,98 \pm 0,15$ & $3,33 \pm 0,45$ & $10,18 \pm 1,34$ \\
Lipase & $10,54 \pm 0,85$ & $11,93 \pm 0,81$ & $3,89 \pm 0,20$ \\
Protease & $4,18 \pm 0,36$ & $4,05 \pm 0,35$ & $9,12 \pm 0,74$ \\
Tripsina & $7,56 \pm 0,43$ & $10,43 \pm 0,75^{\mathrm{a}}$ & $6323,25 \pm 416,81$ \\
Quimotripsina & $6404,70 \pm 375,62$ & $6914,87 \pm 262,58$ & \\
\hline & Bioquímica plasmática & $104,01 \pm 1,28^{*}$ \\
Glicose & $106,15 \pm 6,06$ & $94,29 \pm 3,35$ & $3,18 \pm 0,15$ \\
Proteínas totais & $2,97 \pm 0,18$ & $3,50 \pm 0,15^{\mathrm{a}}$ & $0,74 \pm 0,05$ \\
Albumina & $0,71 \pm 0,07$ & $0,75 \pm 0,03$ & $4,06 \pm 0,27$ \\
Aminoácidos & $3,66 \pm 0,24$ & $4,65 \pm 0,30^{\mathrm{a}}$ & $239,61 \pm 12,97^{*}$ \\
Triglicerídeos & $266,15 \pm 32,94$ & $349,23 \pm 14,99^{\mathrm{a}}$ & $163,76 \pm 18,76$ \\
Colesterol & $141,82 \pm 12,78$ & $141,45 \pm 8,82$ & $166,62 \pm 5,04^{*}$ \\
Glicogênio & $147,35 \pm 11,32$ & $189,26 \pm 6,87^{\mathrm{a}}$ & \\
\hline Glicose & Bioquímica hepática & $134,10 \pm 9,33^{*}$ \\
Proteína & $164,68 \pm 13,97$ & $191,35 \pm 10,49$ & $62,76 \pm 2,70$ \\
Aminoácidos & $66,15 \pm 2,44$ & $58,38 \pm 3,41$ & $97,35 \pm 4,48$ \\
Amônia & $106,25 \pm 5,66$ & $99,24 \pm 2,94$ & $4,10 \pm 0,30$ \\
ALT & $4,04 \pm 0,35$ & $4,23 \pm 0,38$ & $53,00 \pm 6,82$ \\
AST & $57,97 \pm 7,51$ & $49,89 \pm 3,89$ & $561,12 \pm 23,5 *^{*}$ \\
\hline
\end{tabular}

${ }^{1}$ Enzimas digestivas: amilase $=\mu \mathrm{mol}$ glicose hidrolisada por minuto/mg proteína; lipase $=\mu \mathrm{g}$ substrato hidrolisado por minuto/mg proteína; protease $=\mu$ g tirosina hidrolisada por minuto/mg proteína; tripsina $=\mu$ mol TAME hidrolisado por minuto/mg proteína; quimotripsina $=\mu \mathrm{mol}$ BTEE hidrolisado por minuto/mg proteína. Bioquímica plasmática: glicose, colesterol, triglicerídeos=mg/dL; proteína, albumina=g/dL; aminoácidos=mmol/dL. Bioquímica hepática: glicogênio, glicose $=\mu \mathrm{mol}$ glicose/g tecido; proteína =mg/g tecido; aminoácidos, amônia $=\mu \mathrm{mol} / \mathrm{g}$ tecido; ALT (alanina aminotransferase), AST (aspartato amino- transferase) $=\mathrm{UI} / \mathrm{mg}$ tecido. Valores expressos como média \pm erro-padrão da média $(\mathrm{n}=6)$. *Indica diferença significativa da forma tratada quimicamente para a forma in natura do farelo pelo teste F $(\mathrm{P}<0,05)$; Letra indica diferença significativa em relação ao tratamento controle pelo teste de Dunnett $(\mathrm{P}<0,05)$.

A análise da composição corporal dos animais é o reflexo final da utilização dos nutrientes da dieta. Logo, ao final do período experimental, foi observado menor percentual de proteína na carcaça das carpas que receberam o tratamento
TgIN em relação aos demais tratamentos (Tab. 4). Em comparação ao tratamento TgT, a forma in natura do farelo de tungue causou maior deposição de gordura. 
Tabela 4. Composição corporal de juvenis de carpa húngara ao início e após 63 dias de alimentação com dieta à base de proteína de origem animal (controle) ou contendo farelo de tungue in natura ou tratado quimicamente

\begin{tabular}{lcccc}
\multirow{2}{*}{ Variáveis (\%) } & \multirow{3}{*}{ Inicial } & \multicolumn{3}{c}{ Tratamentos dias } \\
\cline { 2 - 4 } & & Controle & TgIN & TgT \\
\cline { 2 - 4 } Matéria seca & $27,22 \pm 0,39$ & $30,99 \pm 0,82$ & $31,72 \pm 0,44$ & $30,51 \pm 0,71$ \\
Matéria mineral & $2,65 \pm 0,08$ & $1,77 \pm 0,04$ & $1,88 \pm 0,04$ & $2,02 \pm 0,14$ \\
Proteína bruta & $15,05 \pm 0,24$ & $14,81 \pm 0,49$ & $13,31 \pm 0,32 \mathrm{a}$ & $14,39 \pm 0,27^{*}$ \\
Gordura & $9,83 \pm 0,72$ & $15,82 \pm 0,79$ & $16,69 \pm 0,32$ & $14,63 \pm 0,38^{*}$ \\
\hline
\end{tabular}

${ }^{1}$ Valores expressos como média \pm erro-padrão da média $(\mathrm{n}=6)$ na matéria natural. *Indica diferença significativa da forma tratada quimicamente para a forma in natura do farelo pelo teste $\mathrm{F}(\mathrm{P}<0,05)$. Letra indica diferença significativa em relação ao tratamento controle pelo teste de Dunnett $(\mathrm{P}<0,05)$.

Estes dados refletem a situação metabólica verificada no fígado e no plasma, culminando com reduzida deposição proteica e aumento no ganho de gordura corporal nos animais do tratamento TgIN. Outras espécies também demonstraram essa tendência ao serem submetidos a percentuais crescentes de ingredientes proteicos vegetais na dieta (Fournier et al., 2004; Pratoomyot et al., 2010). No entanto, um resultado importante obtido neste estudo refere-se ao tratamento TgT, em que as carpas, mesmo evidenciando menor crescimento (-25\%) ao final do período experimental em relação ao tratamento controle, depositaram concentrações semelhantes de proteína e gordura corporal, demonstrando uma eficiente metabolização dos nutrientes vindos dessa ração experimental. Ainda, o teor de matéria seca e o de matéria mineral não foram alterados entre os tratamentos avaliados neste estudo.

\section{CONCLUSÃO}

O tratamento químico do farelo de tungue com vistas a sua detoxificação causou alterações nos níveis de nutrientes e antinutrientes que refletiram sobre o desempenho produtivo, os parâmetros metabólicos e a composição corporal de carpa húngara. A substituição parcial da fonte proteica de origem animal pela forma in natura do farelo de tungue causou prejuízos significativos ao desenvolvimento dos animais. Já os animais arraçoados com a forma tratada quimicamente apresentaram melhor desempenho produtivo e composição de carcaça, o que demonstra a importância do tratamento aplicado sobre esse coproduto para melhoria do seu valor nutricional. Contudo, a detoxificação proposta para o farelo de tungue não foi suficientemente efetiva para igualar os dados de desempenho à ração controle, usada como padrão comparativo.

\section{AGRADECIMENTOS}

Ao $\mathrm{CNPq}$ (processos número 558861/2010-5 e 504592/2010-6) e à FAPERGS (processo número 1008346), pelo auxílio financeiro às pesquisas; à empresa Indústria de Óleos Varela (RS), pela doação do farelo de tungue.

\section{REFERÊNCIAS}

BERGAMIN, G.T.; MARTINELLI, S.G.; DELLA FLORA, M.A.L. et al. Fontes protéicas vegetais na alimentação da carpa húngara. Cienc. Rural, v.41, p.1660-1666, 2011.

BLIGH, E.G.; DYER, W.J. A rapid method of total lipid extraction and purification. C. J. Biochem. Physiol., v.37, p.911-917, 1959.

BOYD, C.E.; TUCKER, C.S. Water quality and pond soil analysis for aquaculture. Alabama: Alabama Agricultural Experiment Station, Auburn University, 1992. 183p.

BRADFORD, M.M.A. A rapid and sensitive method for the quantification of microgram quantities of protein utilizing the principle of protein-dye binding. Anal. Biochem., v.72, p.248-254, 1976.

BUREAU, D.P.; HARRIS, A.M.; BEVAN, D.J. et al. Feather meals and meat and bone meals from different origins as protein source in rainbow trout (Onchorhynchus mykiss) diets. Aquaculture, v.181, p.281-291, 2000. 
EL-SAIDY, D.M.S.D.; GABER, M.M.A. Replacement of fish meal with a mixture of different plant protein sources in juvenile Nile tilapia, Oreochromis niloticus (L.) diets. Aquacult. Res., v.34, p.1119-1127, 2003.

FOURNIER, V.; HUELVAN, C.; DESBRUYERES, E. Incorporation of a mixture of plant feedstuffs as substitute for fish meal in diets of juvenile turbot (Psetta maxima). Aquaculture, v.236, p.451-465, 2004.

GAWLICKA, A.; PARENT, B.; HORN, M.H. et al. Activity of digestive enzymes in yolk-sac larvae of Atlantic halibut (Hippoglossus hippoglossus): indication of readiness for first feeding. Aquaculture, v.184, p.303-314, 2000.

HANSEN, A.C.; ROSENLUND, G.; KARLSEN, O. et al. Total replacement of fish meal with plant proteins in diets for Atlantic cod (Gadus morhua L.) I - Effects on growth and protein retention. Aquaculture, v.272, p.599-611, 2007.

HARDY, R. Utilization of plant in fish diets: effects of global demand and supplies of fishmeal. Aquacult. Res., v.41, p.770-776, 2010.

KAUSHIK, S.J. Nutrient requirements, supply and utilization in the context of carp culture. Aquaculture, v.129, p.225-241, 1995.

KAUSHIK, S.J.; COVÈS, D.; DUTTO, G.; BLANC, D. Almost total replacement of fish meal $y$ plant protein sources in the diet of a marine teleost, the European seabass, Dicentrarchus labrax. Aquaculture, v.230, p.391-404, 2004.

KAUTZ, J.; LYSYK, G.; MONTES D’OCA, M.G.; CLEMENTIN, R.M. Extração do óleo de tungue (Aleuritis fordii) para produção de biodiesel. In: SIMPÓSIO ESTADUAL DE AGROENERGIA E I REUNIÃO TÉCNICA ANUAL DE AGROENERGIA DO RS, 2008, Pelotas. Anais... Pelotas: [s.n] 2008. (Resumo).

KHAN, M.N.; PARVEEN, M.; RAB, A. et al. Effect of replacement of fish meal by soybean and sunflower meal in the diet of Cyprinus carpio fingerlings. Pak. J. Biol. Sci., v.6, p.601604, 2003.
KUMAR, V.; MAKKAR, H.P.S.; BECKER, K. Detoxified Jatropha curcas kernel meal as a dietary protein source: growth performance, nutrient utilization and digestive enzymes in common carp (Cyprinus carpio L.) fingerlings. Aquacult. Nutr., v.17, p.313-326, 2011.

LATTA, M.; ESKIN, M. A simple and rapid colorimetric method for phytate determination. $J$. Agricult Food Chem., v.28, p.1313-1315, 1980

LAZZARI, R.; RADÜNZ NETO, J.; PEDRON, F.A. et al. Protein sources and digestive enzyme activities in jundiá (Rhamdia quelen). Sci. Agric., v.67, p.259-266, 2010.

LIN, S.; LUO, L. Effects of different levels of soybean meal inclusion in replacement for fish meal on growth, digestive enzymes and transaminase activity in pratical diets for juvenile tilapia, Oreochromis niloticus x O. aureus. Anim. Feed Sci. Technol., v.168, p.80-87, 2011.

MAKKAR, H.P.S. Quantification of Tannins in Tree Foliage. Vienna: FAO/IAEA. 2000. 26p.

MEYER, G.; FRACALOSSI, D.M.; BORBA, M.R. A importância da quantidade de energia na ração de peixes. Pan. Aquicult., v.14, p.53-57, 2004.

MINISTÉRIO da Pesca e Aquicultura. Boletim Estatístico da Pesca e Aquicultura Brasil 2010. Disponível em: <http://www.mpa.gov.br>. Acessado em: 11 set. 2012.

MONTES-GIRAO, P.J.; FRACALOSSI, D.M. Dietary lysine requirement as basis to estimate the essential dietary amino acid profile for jundiá, Rhamdia quelen. J. World Aquacult. Soc., v.37, p.388-396, 2006.

NEU, D.H.; BITTENCOURT, F.; SOUZA, B.E. et al. Eugenol como anestésico para juvenis de carpa comum (Cyprinus carpio). In: SIMPÓSIO INTERNACIONAL DE NUTRIÇÃO E SAÚDE DE PEIXES, 3., 2009, Botucatu. Anais... Botucatu: [s.n.] 2009. (Resumo).

OFFICIAL methods of analysis. 16.ed. Arlington, VA: AOAC, 1995. 1137p.

PRATOOMYOT, J.; BENDIKSEN, E.A.; BELL, J.G.; TOCHER, D.R. Effects of increasing replacement of dietary fishmeal with plant protein sources on growth performance and body lipid composition of Atlantic salmon (Salmo salar). Aquaculture, v.305, p.124-132, 2010. 
PRETTO, A. Detoxificação de farelos de crambe e tungue e avaliação na resposta nutricional do jundiá Rhamdia quelen. 2013. 175f. Tese (Doutorado em Zootecnia) - Universidade Federal de Santa Maria, Santa Maria.

TAMASSIA, S.T.J; GRAEFF, A.; SCHAPPO, C.L. et al. Ciprinocultura - o modelo de Santa Catarina. In: CYRINO, J.E.P.; URBINATI, E.C.; FRACALOSSI, D.M.; CASTAGNOLLI, N. (Eds.). Tópicos Especiais em Piscicultura de Água Doce Tropical Intensiva. São Paulo: Sociedade Brasileira de Aquicultura e Biologia Aquática, 2004. p.267-305.
VAN SOEST, P.J.; ROBERTSON, J.B.; LEWIS, B.A. Symposium: Carbohydrate Methodology, Metabolism, and Nutritional Implications in Dairy Cattle. Methods for Dietary Fiber, Neutral Detergent Fiber, and Nonstarch Polysaccharides in Relation to Animal Nutrition. J. Dairy Sci., v.74, p.3583-3597, 1991.

VERDOUW, H.; VANECHTELD, C.J.A.; DECKKERS, E.M.J. Ammonia determinations based on indophenol formation with sodium salicylate. Water Res., v.12, p.399-402, 1978. 